\title{
LAS LECCIONES DE LA CRISIS MEXICANA
}

Juan de Dios González Ibarra

Doctor en Ciencia Política. Pasante Doctor en Economía. Licenciado en Derecho y Administración. Investigador Nacional SNI II. PTC CIDHEM. Tutor Doctoral Facultad de Derecho de la UNAM. Autor y coautor de 40 libros. Mexicano.

Sumario: I. Introducción. -II. Ética general. -III. Conclusiones. -IV. Bibliografía. 


\section{LAS LECCIONES DE LA CRISIS MEXICANA}

\section{Sumario: I. Introducción. -II. Ética general. -III. Conclusiones. -IV. Bibliografía.}

Resumen: En México por la inseguridad pública existe un sentimiento de que vivimos día a día sin saber que nos deparará el mañana, el título mismo del artículo nos propone la reflexión de que gran parte de la solución en la crisis actual radica en que nuestras conductas, así como las que las estudian como son las ciencias del hombre, sociales o del espíritu comenzando por el derecho y, por supuesto, incluyendo los saberes jurídicos, exigen ser espacios primero que nada axiológicos y humanísticos, así como consecuentemente epistémicos o reflexivos, cuya naturaleza primera debe como ser valorativa o sea, que se justifica siempre y cuando se realicen conductas, procesos y resultados éticos y justos conforme a la obtención de valores, pues la crisis actual es producto -como lo sostiene el premio Nobel de economía Joseph Stiglitz- de la voracidad de los especuladores, así como afirmamos nosotros desde el derecho de conductas dolosas de delincuentes de cuello blanco y oscuros, aprovechándose de la incapacidad de la institucionalidad ética y jurídica para evitarlas.

Palabras clave: Crisis, capital ético y social, epistemología.

ABSTRACT: The same title proposes the affirmation to us of which great part of the solution in the present crisis is in which sciences of the man, social or of the spirit beginning by the right and, by all means, including wisdom legal, demand to be practical, values and humanistic spaces, thus like consequently cognitive, whose nature first it must be axiological that is, that is justified as long as conducts are made, processes and right and ethical results conform to the obtaining of values, because the present crisis is product - as it maintains to a Nobel prize of economy- of the inveracity of the speculators, as well as we affirmed we of 
delinquents of white neck, abusing the incapacity of the ethical and legal institutional to avoid it.

Key words: Descriptors: crisis, capital ethics and social, epistemology.

\section{Introducción.}

El derecho axiológica y epistémicamente conlleva la finalidad comprometida de elevar la condición del hombre, por lo que por oposición a la pretendida neutralidad de las llamadas ciencias naturales, duras o exactas, en buena lógica comparten la misma calidad del ser humano que las produce así como la realidad y conocimientos los que existen conforme a fines y medios comprometidos - muy ajenos a lo neutro o ajeno- para el más valioso manejo de la realidad social, esto quedó demostrado con los horrores genocidas de la Segunda Guerra Mundial y sus crímenes nazis jurídicamente perfectos bajo el Estado de derecho positivista legislativo y su pretendida neutralidad ideológica. ${ }^{1}$

En este trabajo distinguiremos entre ética y moral, la primera como el estudio y conocimiento de la segunda la que tiene una naturaleza, entidad u ontidad práctica o de costumbres sociales identificadas con el ethos griego, así hablaremos que los problemas de la moral se resuelven conforme a las acciones reales de los individuos en la sociedad y, los éticos, se refieren a aquellas normas escritas o implícitas y códigos o estatutos establecidos que orientan o norman a esas conductas.

Lo anterior significa que buscando la verdad ${ }^{2}$ y el valor en $\operatorname{los}$ hechos $^{3}$ orientados por autores como Risieri Frondizi, Michele Taruffo o Karl Larenz y, en la práctica por la acertada resolución de las controversias conforme a razón, sapiencia, derecho y valores como justicia, seguridad jurídica o bien común, siguiendo la recomendación aristotélica de que el inicio correcto del conocimiento es buscar la naturaleza íntima, profunda o primera del ser como principio del saber, podemos sostener congruentemente que el deseo de lograr lo establecido

\footnotetext{
${ }^{1}$ VIGO, R. (coord.), La injusticia extrema no es derecho, México, Fontamara, 2008, p. 86.

${ }^{2}$ HÄBERLE, P., Verdad y Estado constitucional, México, UNAM, Instituto de Investigaciones Jurídicas, 2006, p. 59.

${ }^{3}$ FERRER, J., Gascón, M., González, D. y Taruffo, M., Estudios sobre la prueba, México, Fontamara, 2008, p. 179.
} 
conforme la voluntad de construir nuestro Estado Constitucional Democrático y Social tanto en la forma y resultados en concordancia con la organización social, económica y cultural junto con el sistema jurídico, esto es lo que puede explicar de principio tanto a la actividad jurisdiccional $^{4}$ como a la de la ciudadanía y de las políticas públicas, así como desde esta perspectiva constitucional comprometida concientemente - por oposición a la falacia de la neutralidad del juzgador- con impulsar una nueva cultura en los valores conforme a la Constitución y a la ética en lo laboral, empresarial, político, artístico o económico, así como a la información y difusión públicas transparentes con conocimiento que intenta explicar ampliamente esas acciones ciudadanas y jurisdiccionales direccionadas hacia un proyecto de innovación institucional ético y legal.

Esto es confirmado históricamente tanto en lo positivo con casos como el de Sócrates que prefirió la muerte a faltar a las leyes de Atenas, como en lo negativo con quienes cayeron ante la perversión del poder como Carl Schmitt ${ }^{5}$ y Martin Heidegger ${ }^{6}$, porque el fin primero de estas ciencias es y ha sido organizar a la sociedad de una determinada manera siguiendo valores e incluso disvalores dominantes, esto último permitió en el siglo XVIII el surgimiento de la sociedad industrial o capitalista, sin embargo el tratamiento por ausencia de los valores y la carencia de jueces comprometidos con los valores constitucionales democráticos y sociales, también ocasionó males como los que el capitalismo salvaje de la etapa primera de industrialización inglesa generó por carencias axiológicas con los resultados vergonzosos históricamente conocidos, para no hablar de los ecológicos.

En esta lucha exacerbada por la actual crisis entre la ley inhumana del mercado de la oferta y la demanda y los valores del Estado Constitucional Democrático y Social mexicano en construcción, la argumentación que se presenta en este trabajo parte de una posición que se da desde la construcción primera de un cuerpo axiológico y epistémico, ${ }^{7}$ dando seguimiento a los antecedentes lógico-histórico.

${ }^{4}$ SCJN, Código de Ética del Poder Judicial de la Federación, México, CJF, 2004, p. 23.

${ }^{5}$ RÜTHERS, B., Carl Schmitt en el Tercer Reich, Bogotá, Universidad Externado de Colombia, 2004, p. 166. Menciona: "El horror de Schmitt y sus discípulos frente a la tiranía de los valores se funda, posiblemente, en la inclinación interior o la forzada represión de la contribución propia en la múltiple desvalorización del derecho alemán".

${ }^{6}$ GUERRA, R. y YÁNEZ, A., Martín Heidegger. Caminos, México, CRIM. FFL. UNAM. CIDHEM. 2009, p. 94. La filósofa Juliana González en el capítulo "Heidegger y el problema del nazismo" afirma: "la grandeza de Heidegger no impide reconocer la precariedad ética de sus compromisos, alianzas y simpatías biográficas, su complicidad con la hybris demoniaca de su tiempo y su sociedad... (pero) nada puede limitar el reconocimiento al genio de Heidegger, a su originalidad y profundidad, a sus aportes filosóficos irreversibles".

${ }^{7}$ GONZÁlEZ IBARRA, J., Epistemología jurídica, México, Porrúa, 2008, p. 35. 
De conformidad con lo anterior, desde la perspectiva de una indispensable magistratura comprometida con los valores socioeconómicos que la Constitución fundamentalmente contiene para la construcción de una sociedad incluyente en el reparto de la riqueza, oportunidades y cultura nacional, disentimos con que el criterio de que la obra que se considera equivocadamente como iniciadora de la ciencia económica "pura" (por oposición a la que nosotros consideramos como ciencia socioeconómica y cultural) de la primera sociedad industrial en la historia de la humanidad como es la inglesa, sea Una investigación sobre la naturaleza y causas de la riqueza de las naciones editada el 9 de marzo de 1776 del escocés Adam Smith (Kirkaldy, 1723 - Edimburgo, 1790). Por el contrario, consideramos -retando a esa "verdad economiscista"- que del estudio reflexivo de la misma podemos concluir que la preocupación primera como pensador de Adam Smith es la ética, con esto es congruente poder explicar el título y contenido del libro primero "De las causas del progreso en las facultades productivas del trabajo y del modo como un producto se distribuye naturalmente entre las diferentes clases del pueblo", las capacidades organizacionales conforme a valores morales de todas de las naciones y campos de los países, son no solamente las capacidades económicas, como reduccionistamente se intentó presentar.

Documentamos el argumento anterior pues Adam Smith como estudiante del Colegio de Glasgow fue discípulo y admirador del filósofo y profesor de ética Francis Hutcheson autor de la obra System of Moral Philosophy, así la primera obra de Smith de 1759 es Teoría de los sentimientos morales, en donde partió del supuesto de "el sentido moral es natural al hombre", por lo que lógicamente los males del primer capitalismo salvaje y del neoliberalismo actual no pueden atribuirse en paternidad intelectual a él, por el contrario en sus obras siempre está lo ético y lo justo como protagonistas, a partir de lo que él conceptualiza como la simpatía mutua como sentimiento también natural que nos hermana a todos.

La obra que sí es especializada de puntual apego a la economía pura o economicista es la de David Ricardo On the principles of political economy and taxation de 1817, en donde el estudio y explicación sólidamente se circunscribe al campo económico a partir del primer capítulo titulado "Sobre el valor", sin embargo aquí ya estamos en presencia de un manejo reduccionista del valor desde el valor de uso y el de cambio, como podemos observar con David Ricardo la preocupación moral de Smith quedó atrás y, consecuentemente, empezará la interpretación de la realidad preocupada por el lucro reducida a lo solamente económico excluyendo a lo deóntico moral y jurídico, creándose la corriente cognitiva llamada del liberalismo económico en donde domina la ley de la oferta y la demanda sobre leyes éticas y jurídicas de contenidos social. 
En apoyo de lo anterior como criterio nuestro citemos a John M. Ferguson quien en su Historia de la economía (1991:103) afirma: "En verdad, se trata de una historia y crítica de la civilización europea desde la caída del Imperio Romano hasta sus días. La riqueza de las naciones pudo haberse titulado con absoluta exactitud, Historia y crítica de la civilización de la Europa occidental",

En este trabajo donde se intenta reflexionar desde la epistemología y el derecho como argumentación, sobre el papel ético en el control del juzgador conforme la garantía jurisdiccional de la Constitución según Manuel González Oropeza, así como ella está materializada en México en la Suprema Corte de Justicia de la Nación como legítimo Tribunal Constitucional conforme con el pensamiento de Peter Häberle, -magistratura comprometida como agente del cambio positivo en la sociedad-, nos conduce desde los valores hacia la realización de las virtudes en las comunidades del hombre, como sostiene el pensamiento del profesor de la Universidad de Estrasburgo y París Michel Villey o siguiendo al pensador posmoderno de la Universidad de Oxford John Finnis en su obra Natural law and natural rights "la praxis humana y su desarrollo en orden a lograr el florecimiento humano (human flourishing)", es un digno marco en donde discutir la propuestas anteriores, desde la perspectiva interdisciplinaria de la administración e impartición de justicia, axiología y teoría constitucional, socioeconomía y cultura, por lo que atañe a la controversial relación entre ética como base de la deóntica y la moral práctica efectivamente realizada en lo personal, laboral e institucional de la judicatura, desde la perspectiva argumentativa en donde Manuel Atienza combina lógica simbólica, teoría jurídica y práctica legal.

\section{II. Ética general.}

Las teorías éticas clásicas las podemos clasificar ${ }^{9}$ en dos corrientes:

a) teleológicas $y$,

b) deónticas.

Las primeras se guían por los fines o telos, teniendo desde Aristóteles la finalidad de la felicidad, el utilitarismo de Jeremy Bentham y John Stuart Mill con la mayor felicidad para el mayor número conforme con el principio de la mayoría.

\footnotetext{
${ }^{8}$ FERGUSON, J., Historia de la economía, FCE, México, 1991, p. 103.

${ }^{9}$ Camps y otros, Ética de la ciencia y la tecnología en el siglo XXI. UPV/EHU. Bilbao, 1999, p. 188.
} 
Dentro de las deónticas (deon o deber en griego antiguo) encontramos el pensamiento de Emmanuel Kant ${ }^{10}$ con sus imperativos categóricos, así como a los neokantianos dentro de varias escuelas éticas.

El criterio de Karl Popper ${ }^{11}$ es que éste filósofo es "el primer pensador en desarrollar una teoría de la verdad, y de vincular la idea de verdad objetiva... el primer filósofo moral, el primero en desarrollar una teoría crítica del conocimiento humano".

\section{DEL MONISMO AXIOLÓGICO AL SISTEMA DE VALORES}

El anteriormente citado filósofo navarro enfrenta al atomismo axiológico un sistema de valores que compiten, y frente a un monismo axiológico nos encontramos el pluralismo axiológico; sostiene que "En lugar de pensar que las acciones humanas, y en concreto la actividad científica, están regidas por un único valor, o por un valor prioritario, afirmamos que en toda acción científica hay una pluralidad de valores involucrados, conforme a la tesis sistémica recién mencionada"12.

Este autor reconoce que "los economistas, y en particular Adam Smith fueron los primeros en interesarse por la cuestión de los valores".

Por lo que respecta a la dinámica axiológica, a partir de lo que él considera la regla de oro que lo orienta, consistente en "incrementar el grado de satisfacción de los valores positivos y menguar el de los negativos", sostiene este autor de conformidad y a partir de los axiomas de Max Scheler sobre la axiología, que:

La existencia de un valor positivo es en sí misma un valor positivo;

La no existencia de un valor positivo es en sí misma un valor negativo;

La existencia de un valor negativo es en sí misma un valor negativo.

La no existencia de un valor negativo es en sí misma un valor positivo.

Javier Echeverría, distinguiendo doce subsistemas de valores, entre ellos los epistémicos, como rigor, precisión o experiencia, desde la perspectiva del cambio social de valores, nos habla de la revolución axiológica; discrepa de la afirmación monista siguiente de Miguel Martínez: "cada escuela, sistema, doctrina o teoría ética, a su manera, postula un valor

\footnotetext{
${ }^{10}$ KANT, E. Fundamentación de la metafisica de las costumbres. Crítica de la razón práctica. La paz perpetua, México, Porrúa, 2000, p. 67.

${ }^{11}$ POPPER, K., En busca de un mundo mejor, Barcelona, Paidós, 1994, p. 245.

12 ECHEVERRÍA, J., La revolución tecnocientífica, Madrid, FCE, 2003, p. 87.
} 
absoluto: sabiduría o conocimiento (socratismo); bien o belleza (Platón y el neoplatonismo); felicidad racional (Aristóteles y su escuela); virtud (estoicos); deber o ley moral (Kant); placer sensible (hedonismo); placer racional (Epicuro); vida superior (Nietzsche); vida mística (Bergson); supervivencia o sobrevivencia individual (pragmatismo); éxito individual y colectivo (utilitarismo); libertad auténtica (existencialismo); humanidad divinizada (Feuerbach y la Ilustración); persona humana (personalismo)"; por el contrario, afirma, son sistemas de valores que compiten entre sí.

Relacionando esto con nuestro campo de administración e impartición de justicia o jurisdiccional encontramos que no puede ser una simple tecnología por su contenido humanístico, para este autor los valores no son esencias o entidades, sino funciones aplicadas por agentes evaluadores, los valores que tienen que ver con el análisis axiológico de la actividad tecnocientífica son:
1. Básicos
2. Epistémicos
3. Tecnológicos
4. Económicos
5. militares
6. Políticos
7. Jurídicos
8. Sociales
9. Ecológicos
10. religiosos
11. Estéticos
12. Morales

\section{EL DERECHO COMO SUPREMO ORGANIZADOR DE LO COTIDIANO,} CON LA ÉTICA COMO RECTORA SOCIAL

De acuerdo con el constituyente español Gregorio Peces-Barba en su libro Los valores superiores la moralidad pública es el alma que debe mover tanto al poder como al derecho, pues ella constituye la moralidad interna de ellos. Así se convierte en la organizadora del 
derecho, quien por medio de la institucionalidad deviene en el gran organizador social, pues necesita imperar la ley del más débil, no la ley del mercado, la inhumana ley de la oferta y la demanda; es por ello que F. Carnelutti en su Arte del derecho sostiene que entre el homo economicus que egoístamente no quiere cuidar nada fuera de sus intereses y, el homo moralis que no puede separar el propio bien de los demás, entre el lobo y el cordero está el puente transformador "atrevidísimo" llamado derecho, la línea recta que une a los dos puntos.

El científico mexicano García Máynez por la ruta kantiana del sapere aude se anticipó al concepto de inteligencia emocional del profesor de Harvard H. Gardner, que muchos años después (a principio de los años ochenta) desarrollaría este profesor de la Universidad de Harvard.

Recordemos que el sentimiento nos refiere al pensamiento kantiano o neokantiano de la Escuela de Marburgo con Ernest Cassirer a la cabeza, retomando a E. Kant; éste se rebela contra el racionalismo cartesiano, levanta la bandera de la totalidad cognitiva que incorpora a la intuición y a la emoción que nos permiten identificar directamente al acto de injusticia por la reacción de todo nuestro ser cognitivo-sentimental; tal es el caso ante el golpe de un hombre (identificado directamente como perverso) dado a un niño de tres años.

Se distingue entendimiento de razón; el primero toma a la intuición como recurso cognitivo que nos permite descubrir la verdad; la segunda, al razonamiento fundamentalmente en sus dos formas, deductivo e inductivo, como capacidad humana dirigida hacia la verdad.

En la historia ético jurídica se dio la promulgación de la Ley Antimonopolios Sherman de 1890, producto de los abusos y las quejas de la opinión pública ante prácticas sin escrúpulos de empresas dominantes, durante la crisis económica de 1929 y el combate del New Deal contra el libertinaje del mercado. En México el cardenismo con sus acciones a favor de las clases más necesitadas en la fábrica y el campo.

Sólo la libertad en los valores nos permitirá en México obtener otros valores como son la seguridad ciudadana, equidad, justicia y armonía para poder impulsar la cultura de los mismos en la educación.

\section{LAS LUCHAS DESDE DIVERSAS PERSPECTIVAS ÉTICAS}

En la ciencia del derecho no podría faltar la lucha entre las diversas interpretaciones; así, ante un padre de ella como ciencia ética económico-administrativa quien es Adam Smith, que afirmando como mencionamos que el hombre tiende naturalmente hacia la moral, desde la teoría del valor trabajo o el reconocimiento de que éste es el origen y el único que agrega más valor del que recibe, en la obra citada anteriormente Investigación sobre la naturaleza y causas de la riqueza de las naciones, sostiene en el capítulo segundo que en el hombre existe también 
una propensión natural al cambio, misma que se "se halla estimulada por el egoísmo y conduce a la división del trabajo"; ésta produce un incremento en la eficiencia del mismo.

La afirmación ya esbozada de que los que consideran que Adam Smith cínicamente glorifica al egoísmo del hombre, desconocen o no desean aceptar lo contrario conforme su elevada estima sobre la simpatía y fraternidad connaturales al hombre con la justicia y la benevolencia, como fundamentos sociales según R. Frederick; esto demostrado en los hechos y palabras, pues falleció sin poseer una gran riqueza; "apenas dejó fortuna, no obstante disfrutar de ingresos relativamente importantes, y sólo la muerte reveló su filantropía”.

Recordemos que mencionamos ya que antes de esta obra escribió, en 1759, su libro Teoría de los sentimientos morales, el que "marca un derrotero importante en su vida. Ese libro es considerado desde los primeros momentos como una obra maestra. Le consagra intelectualmente y, tras la fama, va en aumento el número de estudiantes ansiosos de oír sus explicaciones".

A mayor abundamiento, el discípulo del filósofo Francis Hutchenson, siguiendo su vocación axiológica consiguió en 1752 ser nombrado profesor de la cátedra superior de filosofía moral; en este libro se muestra a un filósofo práctico preocupado por la humanidad desde la perspectiva de la naciente sociedad industrial, capitalista o burguesa.

Otro tanto ocurrirá con David Ricardo; conforme su obra, al estudiarla, no encontramos a un sujeto amoral preocupado por elevar solamente la ganancia; por el contrario, conforme la teoría del valor trabajo, reconoce -con honestidad reconocida por Karl Marx- esta calidad genética valoral única del ser humano llamado trabajador.

\section{LA FALACIA DE LA ADMINISTRACIÓN GENERAL Y DE JUSTICIA}

\section{NEUTRA}

Empecemos la reflexión desde la afirmación socioeconómica de Friedman de 1966, repetidas en innumerables ocasiones y foros: “¿Qué significa decir que el ejecutivo de la empresa tiene 'una responsabilidad social' en cuanto hombre de negocios?; si esa afirmación no es pura retórica, tal cosa significa que tiene que actuar de alguna manera que no corresponde a los intereses de sus patronos... En un sistema de libre empresa y propiedad privada, un ejecutivo es un empleado de los propietarios del negocio. Es directamente responsable ante sus

patronos. Esa responsabilidad consiste en dirigir el negocio de acuerdo con los deseo de 
aquellos, que generalmente se reducirán a ganar tanto dinero como sea posible, siempre que se respeten las reglas básicas de la sociedad, tanto las prescritas por la ley como por la costumbre" como considera I. Camacho.

La posición anterior niega responsabilidades sociales de la empresa; es una visión miope y amoral, que desconoce que toda organización se encuentra abierta ante un entorno socioeconómico al cual se debe e interactúa ${ }^{13}$.

Las reacciones ante el criterio de Friedman, en el sentido de que la postura ética de "la responsabilidad social de la empresa es subversiva", a pesar de contar con el respaldo de su premio Nobel de Economía, no se hicieron esperar; no podemos aceptar que la empresa esté sólo al servicio de los propietarios; por el contrario, sus compromisos morales empiezan en la sociedad desde la conceptualización general de los stakeholders, por diferencia específica con los accionistas; el beneficio económico como fin último de la empresa se valora actualmente como amoral, siendo la ética no sólo necesaria sino por el contrario rentable, pues dentro de los bienes intangibles que dominan a los tangibles encontramos a la fidelidad de los clientes, la actitud de los trabajadores comprometida con una empresa moral, la certidumbre de los accionistas de que su dinero está respaldado no sólo por la competitividad, eficacia, eficiencia, productividad, sino ante todo por el respeto a un código ético que todos respetan.

El empleado y funcionario público mexicano tiene responsabilidades conforme el artículo 108 constitucional por sus actos u omisiones en que incurra en el desempeño de sus funciones, en lo particular del ejercicio jurisdiccional aplica tanto lo legal y lo moral, claramente expresado a partir de agosto de 2004 en el código de ética judicial federal.

Por fortuna tenemos también actos evidentes del giro de la apreciación de la ciencia como producto intencionado de la actividad humana; tal es el caso del Premio Nobel Mario Molina, profesor del MIT, cuyos descubrimientos de los productos comerciales que ocasionaban el problema del agujero de la capa de ozono lo enfrentaron conforme a sus palabras, "a un problema de ética superior"; a la visión de una tecnología que no requiere de la ética, enfrentamos el criterio de que "los espacios en los que los seres humanos llevan a cabo sus acciones tecnológicas pueden estar cargados de valores y no pueden ser considerados como axiológicamente neutros"14 (López et al, 1997:27); la ingenuidad o, mejor dicho, la ignorancia de la existencia de valores no excusa su cumplimiento conforme la máxima jurídica aquí aplicable.

\footnotetext{
${ }^{13}$ PAZ, V., "Elementos para una relación equilibrada entre la estructura y el sujeto en estudios de análisis sociológico", Veredas, México, UAM-X. DCS. Año 10, 2009, p. 57.

${ }^{14}$ LÓPEZ CEREZO, J. et al, Filosofía de la tecnología, Madrid, OEI. Teorema, 1997,
} 
La iniciativa privada generadora de empresas, primero está al servicio de la sociedad o no está realmente al servicio de nada, salvo al mezquino enriquecimiento personal, de aquel individuo que de ser tan rico es solamente un pobre millonario, cumpliéndose la máxima de Oscar Wilde de que "el pillo conoce el precio de todo y el valor de nada".

\section{Primeras conclusiones.}

La respuesta a si la ética tiene cabida en el espacio jurisdiccional federal ya está dada y documentada desde agosto de 2004 por la SCJN, en contra de la posición kantiana y conforme a la argumentación lógico-histórica anteriormente expresada esto es un avance para la vida nacional; pues gracias a la sociedad de la información y del conocimiento, las prácticas inmorales descubiertas en segundos se difunden por la globalidad imperante; los valores como independencia, imparcialidad, objetividad, profesionalismo y excelencia han sido establecidos como obligatorios en la acción jurisdiccional, así la transparencia de la magistratura federal pasa forzosamente por la ética ante una realidad polivalente.

Salvo en la delincuencia organizada, es imposible considerar una cultura de las organizaciones sin ética; la excelencia de ellas pasa forzosamente por ella, en lo privado como integridad de la totalidad socioeconómica desde el Estado Constitucional, se aceptan según Camacho los siguientes criterios de moralidad en la conducta del empresario comprometido con el bienestar de la sociedad: eficacia, legalidad, profesionalidad, honestidad, bien común, confidencialidad, fidelidad a responsabilidades concretas, buena fe, evitar conflictos de intereses y respeto a la integridad de las personas.

\section{El derecho como supremo organizador social versus la ley del mercado de la}

\section{oferta y la demanda}

El derecho debe ser el gran organizador social, pues necesita imperar la ley del más débil, no la ley del mercado, la inhumana ley de la oferta y la demanda, es por ello que Carnelutti sostiene que entre el homo economicus que egoístamente no quiere cuidar nada fuera de sus intereses y, el homo moralis que no puede separar el propio bien de los demás, entre el lobo y el cordero está el puente transformador "atrevidísimo"15 llamado derecho, la línea recta que une a los dos puntos.

${ }^{15}$ Ídem. pp. 22-23. 
Recordemos que Don José María Morelos y Pavón fue quién elaboró el 14 de septiembre de 1813 el primer documento de prospectiva jurídica mexicana, como amorosa acta de nacimiento para un país todavía sin nacer llamado Sentimientos de la Nación, ahí señaló que "la buena ley es superior a todo hombre...la que debe moderar la opulencia y la indigencia, de tal suerte que aumente el jornal del pobre, que mejore sus costumbres, aleje la ignorancia, la rapiña y el hurto...Sólo distinguirá a un americano del otro, el vicio y la virtud, no se admitirá en la nueva legislación la tortura", herederos de ese espíritu visionario el abogado educado en los valores honra con un acto de justicia su compromiso hacia el más débil.

Recordemos que el sentimiento nos refiere al pensamiento kantiano, ${ }^{16}$ éste se rebela contra el racionalismo cartesiano, levanta la bandera de la totalidad cognitiva que incorpora a la intuición y a la emoción que nos permiten identificar directamente al acto de injusticia por la reacción de todo nuestro ser cognitivo-sentimental, tal es el caso ante el golpe de un hombre (identificado directamente como perverso) dado a un niño de tres años.

Se distingue entendimiento de razón, el primero toma a la intuición como recurso cognitivo que nos permite descubrir la verdad, la segunda al razonamiento fundamentalmente en sus dos formas deductivo e inductivo como capacidad humana dirigida hacia la verdad.

En la historia ético jurídica se dio la promulgación de la Ley Antimonopolios Sherman de 1890, producto de los abusos y las quejas de la opinión pública ante prácticas sin escrúpulos de empresas dominantes, la crisis económica de 1929 y el combate del New Deal contra el libertinaje del mercado.

\section{Dialéctica de los valores}

De allí la afirmación de Hegel en su obra Introducción a la historia de la filosofía de que "es el movimiento más elevado de la razón en el que todas las apariencias pasan de una a otra y en donde todo presupuesto es superado". ${ }^{17}$

Aquí la dialéctica nos permite comprender la dinámica del movimiento hacia los valores por medio de la tesis, antítesis y síntesis valorativa, penetrar de la forma al fondo en donde no es posible la existencia de formas sin sustancias y dialécticamente sustancias sin formas, es el reconocimiento de la negación como principio del movimiento destructor y constructor hacia la síntesis como un paso más hacia la persecución de los valores.

\footnotetext{
${ }^{16}$ KANT, E. Crítica de la razón pura. México, Porrúa, 1991, p. 142. También consúltese la obra de Ernest Cassirer Kant, vida y doctrina, Fondo de Cultura Económica, México, 1993, la primera edición en idioma alemán es de 1918.

${ }^{17}$ HEGEL, G. Introducción a la historia de la filosofía. Buenos Aires, Aguilar Argentina, 1975. p. 52.
} 
Desde la dialéctica hegeliana se contempla el desenvolvimiento de la historia de la humanidad desde lo sensible hasta el saber absoluto del hombre, en el que el espíritu se reconoce a sí mismo conforme una epistemología que nos lleva a afirmar que "al entenderlo es poder verlo como algo que necesariamente tenía que ocurrir", ${ }^{18}$ en consecuencia la obtención y persecución de valores ${ }^{19}$ es algo que por necesidad debe producirse humanamente pues "las preguntas sobre la justicia son preguntas morales" según Robert Alexy.

Debemos precisar que "Hegel llama espíritu subjetivo a la razón que se expresa en los actos de cada individuo, y espíritu objetivo a la razón que se expresa en las leyes e instituciones de la sociedad", ${ }^{20}$ conforme a la categoría primaria del ser valoral por eliminación se puede llegar a la nada en donde la categoría devenir o cambio contiene al ser y a la nada, lo que es y está dejando de ser, esto implica la negación de lo absoluto desde la perspectiva de Heráclito de Éfeso de que todo cambia menos el cambio, que el ser implica su negación o contrario, así el valor justicia está "abrazado" con el disvalor de la injusticia cómo tesis y antítesis y, se consigue una síntesis, por medio de la resolución o sentencia jurisdiccional que toma en cuenta ambas posiciones encontradas bajo las normas sustantivas y adjetivas.

Lo anterior es un reconocimiento de que la contradicción es la fuerza que mueve a todas las cosas naturales y espirituales, el entendimiento de esto "permite la formulación de una lógica sobre el principio negativo que por un movimiento dialéctico se transforma en positivo y que es mucho más fecundo que el principio positivo de identidad de la lógica formal, que se revela incapaz de explicar el movimiento íntimo de la naturaleza". ${ }^{21}$

En donde está presente el reto de la alienación como forma negativa desde y en los valores, misma que el hombre debe superar pues, esta implica la cosificación o extrañamiento antikantiano de lo humano, la corrupción de su naturaleza dignamente humana irrepetible negada por la perversión disvaloral de su sustancia de fin único e irrenunciable ${ }^{22}$ y no de medio prostituible, comercializable con la corrupción por el dinero y el poder.

\section{La libertad en los valores}

\footnotetext{
${ }^{18}$ HARTNACK, J. Breve historia de la filosofía. Madrid, Ediciones Cátedra, 1996. p. 215.

${ }^{19}$ ALEXY, R. y BULYGIN, E. La pretensión de corrección del derecho. La polémica sobre la relación entre derecho y moral. Bogotá, Universidad Externado de Colombia, 2001. p.115.

${ }^{20}$ HARTNACK, J. Ibídem, p. 215.

${ }^{21}$ HEGEL, G., Opus cit. p. 11.

${ }^{22}$ HARTNACK, J., Op. cit. p. 207.
} 
La libertad axiológica del hombre implica que al ser racional puede actuar con base en el imperativo categórico kantiano que nos ordena "obra sólo según aquella máxima que puedas querer al mismo tiempo que se convierta en ley universal", en consecuencia en la naturaleza primera o más íntima del hombre existe la tendencia al bien, o sea, a los valores.

La lucha cotidiana por los valores, su persecución permite conservar la más íntima naturaleza humana pues "la libertad se ejerce siempre ante una situación dada" 23 que, como mencionamos, exige e implica la dignidad, su legitimidad de ser hombre nos impone alcanzarlos para mantener nuestra propia naturaleza, al igual que una persona, árbol o cualquier otro ser, los valores cambian su forma de manifestarse o actualizarse sin que pierdan entidad, cosidad o quididad, siendo su tiempo y espacio el deber ser, así desde la reflexión afirmamos a contrario sensu que un mundo sin valor no tiene posibilidades de existir, la experiencia histórica lo demuestra y basta señalar que el origen y objetivo del derecho es acercarse a ellos, son el principio y fin de éste.

III. Conclusiones.

De acuerdo con lo anterior podemos afirmar que "conocer el bien de algo, conocer su virtud propia o areté era, en efecto, conocer su naturaleza propia, su función específica: aquello que le hace 'ser lo que es'. Conocer el bien del hombre, su telos y areté obligaba a conocer el ser propio del hombre, su tarea, su obra y función específica”24

Una demostración de la existencia plena de los valores la podemos encontrar en que no ha existido momento de la humanidad en que se carezca de ellos, los valores nos acompañan siempre y mueren con nosotros, otra puede ser la que señala que es imposible imaginar una sociedad o persona sin valores o principios, tal sería la negación de la vida misma de ellos.

La presencia valoral de una misma persona y de un árbol se da de diferentes maneras desde las normas jurídicas, ecológicas o estéticas, así las cantantes excelsas llamadas "divas" se actualizan o existen ante nosotros los melómanos por los valores de su canto, su voz, sin embargo ellas son seres biopsicosociales que necesitan, por razones de existencia y sobrevivencia, comer, respirar, pensar y autoreproducir cotidianamente sus células.

El naranjo que conceptualizamos como árbol también existe de varias maneras con sus procesos clorofílicos, la captación de agua, absorción de minerales como el nitrógeno, fósforo y potasio y cambia con las estaciones del año y su edad, desde la perspectiva ecológica ese ser se contempla conforme con los valores humanos.

\footnotetext{
${ }^{23}$ GONZÁLEZ, J. Ética y libertad. México, FFL. UNAM, 1989. p. 211.

${ }^{24}$ Ibidem. p. 297.
} 
El mundo del deber ser (este como presente y futuro, hoy y mañana: integra dialécticamente esos dos modos cronológicos) es aquel que construimos o materializamos con nuestro mejor pasado y tradiciones (estas consisten en preservar lo valioso del pretérito), considerando que "ente los seres ideales hay una especial casta de ellos con particulares características: los valores" 25 el presente y nos sirve para dirigirnos hacia el futuro valioso, así como el gato epistémico de Chester en Alicia en el país de las maravillas sostiene con absoluta verdad o entidad que aquellos que no saben hacia donde van ni siquiera tienen la posibilidad de poder perderse, ${ }^{26}$ sin valores no tenemos siquiera la posibilidad de extraviarnos, este universo social lo podemos "tocar, perseguir, distinguir" con el recurso de nuestra voluntad humana, las ciencias humanas o del espíritu se distinguen de las de la naturaleza por su forma de existir, manifestarse y construirse desde la comprensión humana.

Sólo la libertad en los valores nos permitirá en México obtener otros valores como son la seguridad ciudadana, equidad, justicia y armonía para poder impulsar la cultura de los mismos en la educación.

En el transcurso de esta investigación que nos remontó desde el Código de Hamurabi (que en el año de 1800 a. C. ya condenó a los comerciantes deshonestos) hasta el último artículo de las revistas especializada en derecho, política y administración, siempre en los muchos libros y autores consultados estuvo la presencia constante de gigantes de la reflexión.

Citamos a Sócrates, Aristóteles, J.J. Rousseau como contractualista, Adam Smith como profesor de filosofía moral en Glasgow, E. Kant con su deontología y sus imperativos categóricos de obrar de tal manera que tu motivo volitivo se pueda transformar en una ley universal, la dignidad de la persona pues es irrepetible y única fin en sí misma y no medio pues no es mercancía y el actuar como súbdito y soberano de un reino ideal de fines, ${ }^{27}$ con los disvalores de la violencia y el engaño como formas básicas del hacer daño a los demás.

J. Bentham y J. S. Mill con su utilitarismo de las consecuencias o teleológico, la ética protestante como bendición divina al trabajo como algo sagrado, F. Nietzsche con su lucha entre las virtudes, Ch. Peirce, W. James, John Dewey y R. Rorty desde el pragmatismo, Max Scheler y Nicolai Hartmann desde el objetivismo ético, el liberalismo de R. Nozick y el igualitarismo de J. Rawls, así como el absolutismo, relativismo y el relativismo pluralista, el individualismo y socialismo, así como la condena al "negocio es el negocio" como campo

\footnotetext{
${ }^{25}$ RECASÉNS SICHES, L. Filosofia del derecho. México, Porrúa, 1997, pp. 58-65.

${ }^{26}$ CARROLL, L. Alicia en el país de las maravillas. México, Porrúa, 1992, p. 32.

${ }^{27}$ FREDERICK, R. Ibidem, p. 5.
} 
amoral que no respeta normas o la basura seudo filosófica de "ganador o perdedor" como medida social del valor humano.

En fin para comprender la actual crisis y sus relaciones con la ética y el derecho, pudimos subirnos en los hombros de gigantes para poder contemplar mejor el horizonte axiológico de la sociedad desde la aplicación kantiana o analítica arma de combate del prejuicio de "la ética de los negocios es mucho negocio y muy poca ética"; de la empresa desde la Responsabilidad Social de la Empresa o Corporativa (RSE) surgida en los sesenta con sus cuatro normas éticas:

a) ser rentables;

b) acatar la ley;

c) tener prácticas éticas y;

d) ser buenas ciudadanas corporativas. ${ }^{28}$

Comprender dentro de la crisis actual que amenaza con ampliarse aún más que la ética es un seguro para la propia actividad jurisdiccional, justiciables, comunidad, empresa, consumidores, trabajadores, accionistas y directivos, la administración es moral o no es administración pues al ir en contra de los valores representa una agresión contra la sociedad como lo demostró la crisis de hoy y, consecuentemente, un atentado contra la RSE, niega la naturaleza primera o natura rei de la empresa que es la de crear valor en lo general y valores en lo particular, así contra natura se convierte de actividad administrativa en infractora, de supuesta creadora de valor en su contrario que son los disvalores, no es pues sino engaño o violación a la sociedad y dignidad humana.

Confirmando que la naturaleza primera que nos explica el ser o ente organizacional es la producción de valor, lo tenemos en la delincuencia organizada la que a pesar de utilizar técnicas organizacionales incluso muy avanzadas, esta ausencia axiológica impide que sea, de principio conceptualizada como empresa, pues desde Aristóteles sabemos que aquello que va contra la propia naturaleza corrompe al ser lo aleja de su fin, causa, origen y valores es decir de su naturaleza primaria, así la delincuencia organizada por la causa de que no crea valores sino por el contrario en el caso de los narcóticos disvalores como dependencia, intoxicación, riesgos a la salud moral, ética, social y legalmente está condenada contando por su propia naturaleza como antídoto contra ella a una organización superior de la justicia eficaz.

Así la crisis nos deja la lección de que el problema de la sociedad del conocimiento desde lo privado y lo público no sólo es incrementar la productividad, competitividad, calidad, precio y servicio sino cultivar los activos intangibles dentro de ellos la lealtad, confianza, el

\footnotetext{
${ }^{28}$ Idem, p. 168.
} 
valor de los sustentable, el compromiso del trabajador y el cliente, para esto la ética es indispensable conforme la Responsabilidad Social de la Empresa y una institucionalidad que requiere ser fortalecida.

En lo privado con la convicción de que el consumidor prefiere y otorga su confianza a las empresas éticas, nos manifestamos en contra de la posición de que: "la ética de los negocios es mucho negocio y muy poca ética"; en contra de la empresa ideológicamente amoral o "neutra", combatida desde la responsabilidad social corporativa (RSC) o responsabilidad social de la empresa (RSE); surgida en los sesenta con sus cuatro normas éticas: a) ser rentables; b) acatar la ley; c) tener prácticas éticas y; d) ser buenas ciudadanas corporativas.

En lo público nos quedamos con el criterio de que la crisis mostró las debilidades éticas y jurídicas del sistema global y que se debe intervenir reflexivamente a profundidad. Como esto impactará generacionalmente consideramos que es un compromiso para la universidad pública, el que en cada unidad de enseñanza-aprendizaje del currículum, se incluyan los contenidos éticos específicos de cada área del saber organizacional: derecho, dirección, finanzas, mercadotecnia, etc. Sin que se pretenda separar la ética como unidad de enseñanza aprendizaje particular, esto lo desnaturalizaría. Enseñar con ejemplos de casos que demuestren que la ética es un seguro para la propia empresa, consumidores, trabajadores, accionistas y directivos, la administración es moral o no es administración sino engaño o violación a la sociedad y dignidad humana.

Debemos ayudar a construir en nuestras universidades e instituciones el paradigma emergente, que sostiene que el objetivo de la sociedad del conocimiento no sólo es incrementar la productividad, competitividad, calidad, precio y servicio; sino cultivar los activos intangibles dentro de ellos la lealtad, confianza, justicia, derecho, salud, estabilidad, honestidad, el compromiso del trabajador y el cliente; para esto la ética es indispensable pues tiene que ver con las conductas personales de cada miembro de la ciudadanía.

De acuerdo con lo anteriormente documentado y argumentado, necesitamos con la ayuda y creatividad de todos, - -respetando los matices de las diversas instituciones-, incluir de inicio en los programas de las currícula de la carrera del abogado el estudio de la ética de lo jurisdiccional y de la postulancia, en, por y para la mejor administración de justicia, como conocimiento formativo indispensable para que el futuro profesional que desde la acción jurisdiccional y el litigio tendrá en sus manos la vida, honor, bienes y esperanzas de los justiciables sea un juzgador ético creador real de valores para el cambio axiológico de nuestra realidad conforme nuestro Estado Constitucional Democrático y Social en construcción. 


\section{Bibliografía.}

ATIENZA, M., Introducción al Derecho, México, Fontamara, 2006.

BWEROUR, J., Ética en los negocios. Bilbao, CUCJ, 2002.

CAMACHO, I. et al., Ética de la empresa. Bilbao, Desclée De Brouwer. CUCJ, 2002.

CAMPS, V y otros, Ética de la ciencia y tecnología en el siglo XXI. Bilbao, UPV/EHU, 1999.

CARROLL, L., Alicia en el país de las maravillas. México, Porrúa, 1992.

CASSIRER, E., Kant, vida y doctrina. México, Fondo de Cultura Económica, 1993.

CASTILlO CLAVERO, A. et al., Introducción a la economía y administración de empresas. Madrid, Ediciones Pirámide, 2003.

ECHEVERRÍA, J., Ciencia y valores, Madrid, Ediciones Destino, 2002.

ECHEVERRÍA, J., La revolución tecnocientífica, Madrid, Fondo de Cultura Económica de España, 2003.

FERGUSON, J., Historia de la economía, México, Fondo de Cultura Económica, 1991.

FERRAJOLI, L., Los fundamentos de los derechos fundamentales. Madrid, Editorial Trotta, 2001.

FERRER, J. et al. Estudios sobre la prueba, México, Fontamara, 2008.

GARDNER, H., Estructuras de la mente. La teoría de las inteligencias múltiples. México, Fondo de Cultura Económica, 1987.

GÓMEZ, C., Doce textos fundamentales de la Ética del siglo XX. Madrid, Alianza Editorial, 2002.

GÓMEZ-HERAS, J., Ética en la frontera. Madrid, Editorial Biblioteca Nueva, 2002.

GONZÁLEZ, J., Ética y libertad. FFL. México, UNAM, 1989.

HÄBERLE, P., El Estado constitucional. México, IIJ. UNAM, 2003.

HÄBERLE, P., Verdad y Estado constitucional, México, IIJ. UNAM, 2006.

HABERMAS, J., Conocimiento e interés. Madrid, Taurus, 1968.

HABERMAS, J., Facticidad y validez. Madrid, Trotta, 1998.

HARTNACK, J., Breve historia de la filosofia. Madrid, Ediciones Cátedra, 1996.

HEIDEGGER, M., Ser y tiempo, Madrid, Trotta, 2006. 
HEGEL, G., Introducción a la historia de la filosofía. Buenos Aires, Aguilar Argentina, 1975.

JHERING, R., La lucha por el derecho. México, Porrúa, 1998.

LARROYO, F., Ética. México, Porrúa, 1978.

LÓPEZ CEREZO, J. et al., Filosofía de la tecnología. Madrid, OEI. Teorema, 1997.

MARK FRUIN, W., Las fábricas del conocimiento. México, Oxford University Press, 2000.

MARTÍNEZ HUERTA, M., Ética con los clásicos. México, Plaza y Valdés Editores, 2001.

OEI, La educación en los valores en Iberoamérica. Foro iberoamericano sobre educación en valores. Madrid, OEI, 2001.

PÉREZ, C. y Bolaños, A., "Pistas para entender el derrumbe", Madrid, El País, Suplemento Babelia, 6 de junio, 2009.

POPPER, K., En busca de un mundo mejor. Barcelona, Paidós, 1994.

Rüthers, B. Carl Schmitt en el Tercer Reich, Bogotá, Universidad Externado de Colombia, 2004.

SÁNCHEZ VÁZQUEZ, A., Ética. México, Grijalbo, 1989.

SEN, A., Sobre ética y economía. Madrid, Alianza Universidad, 1989.

SMITH, A., Teoría de los sentimientos morales. México, Fondo de Cultura Económica, 1992.

STIGLITZ, J., El malestar de la globalización. Madrid, Taurus, 2002. Madrid.

STIGLITZ, J., “Cómo llegamos a este desastre? El botín de los especuladores”, México, Memoria, No. 235, abril - mayo 2009.

VIGO, R. (coord.), La injusticia extrema no es derecho, México, Fontamara, 2008.

Juan de Dios González Ibarra es Doctor en Ciencia Política. Pasante Doctor en Economía. Licenciado en Derecho y Administración. Investigador Nacional SNI II. PTC CIDHEM. Tutor Doctoral Facultad de Derecho de la UNAM. Autor y coautor de 40 libros. Mexicano. Correo electrónico: jdgiba@correo.xoc.uam.mx 